\title{
3-D multidetector computed tomography in reoperative cardiac surgery
}

\author{
Tsuyoshi Kaneko ${ }^{1}$, Micheal L. Steigner ${ }^{2}$, Igor Gosev ${ }^{1}$, Sary F. Aranki ${ }^{1^{*}}$ \\ ${ }^{1}$ Department of Cardiac Surgery, Brigham and Women's Hospital, Boston, USA \\ ${ }^{2}$ Department of Radiology, Brigham and Women's Hospital, Boston, USA \\ Email: saranki@partners.org
}

Received 19 May 2013; revised 27 June 2013; accepted 14 July 2013

Copyright (C) 2013 Tsuyoshi Kaneko et al. This is an open access article distributed under the Creative Commons Attribution License, which permits unrestricted use, distribution, and reproduction in any medium, provided the original work is properly cited.

\begin{abstract}
Reoperative cardiac surgery is becoming more common surgery although it carries significant risk due to possible injury to vital structures under the sternum. Three-dimensional multidetector computed tomographic angiography (3-D MDCTA) allows identifying the relationship between the sternum and the mediastinal structures. Evidence shows that 3-D MDCTA guides surgical strategy and enables to perform this challenging surgery safely.
\end{abstract}

Keywords: 3-D MDCTA; Reoperative Cardiac Surgery

\section{INTRODUCTION}

Reoperative cardiac surgery carries a significantly higher risk compared to first time surgery. Several reasons exist; technical difficulties include reoperative sternotomy, mediastinal dissection and higher risk in the reoperative population. However, the cardiac surgeons are facing more and more reoperations, given the longer expectancy in the modern era. The recently published mortality rate for reoperative cardiac surgery in previous coronary artery bypass graft surgery (CABG) has ranged from $2.5 \%$ to $8.3 \%$ [1-7]. The major concern during sternal reentry in these patients is the potential injury to the cardiac structures (right ventricle), previous grafts, innominate vein and Aorta. Surgical strategies, such as interposition of the lungs in the left internal mammary artery (LIMA) [8] or no dissection technique [9] have been described in the literature, but do not eliminate the chances of injury to these structures.

Contrast-enhanced multidetector computed tomographic angiography (MDCTA) has emerged as a useful method to evaluate heart and mediatinal structures [10-11]. In addition, three-dimensional (3-D) volume rendering al"Corresponding author. lows detailed identification of the previous grafts as well as the right ventricle and Aorta.

The aim of this paper is to support the usage of 3-D MDCTA for preoperative evaluation for reoperative cardiac surgery.

\section{METHODS}

\subsection{3-D MDCTA}

State-of-the-art MDCTA for redo sternotomy typically is performed with 64 - 320 detector row CT scanners. Helical acquisitions are performed from above the clavicular heads to the base of the heart with thin slice collimation $(0.5-1.0 \mathrm{~mm})$ at either $100-120 \mathrm{kV}$ and at least $350 \mathrm{~mA}$. Current scanners employ z-axis tube current modulation as an option for the $\mathrm{mA}$ adjustment. Since small vessel $\mathrm{CT}$ angiography requires high contrast to noise ratios, the highest available concentration of contrast $(370 \mathrm{mg} / \mathrm{dL})$ is injected at high flow rates $(4.5-6$ $\mathrm{ml} / \mathrm{sec}$ ). Volume of contrast is determined by the scan time varying from $80-100 \mathrm{ml}$. B-blockade for heart rate control and nitroglycerine for vasodilation are typically not required for the assessment of vessel patency and course; however, these techniques are favored if stenosis evaluation of the prior bypass grafts is paramount. Since bypass grafts don't move with the same velocity as native coronary arteries, acquisitions can typically be performed with prospective gating with a single phase of the cardiac cycle. Dynamic assessment of retrosternal structures has recently been described as an adjunct to the proximity assessment <ref Malguria, et al. "Static and Cine CT Imaging to Identify and Characterize Mediastinal Adhesions as a Potential Complication Undergoing Redo Sternotomy". AJR ACCEPTED FOR PUBLICATION NOT YET IN PRESS. This technique requires retrospective gating at the expense of a higher radiation exposure; however, additional studies are required to determine its value. 


\subsection{Interpretation of the 3-D MDCTA}

Preoperative evaluation of 3-D MDCTA allows the following assessment.

1) Proximity of LIMA and Other Grafts in Relation to the Sternum.

2) Adhesion of the Right Ventricle (RV) to the Sternal Bed (Especially in Light of Pulmonary Hyper Tension).

3) Location of the Innominate Vein and Aorta.

Distance of $<1 \mathrm{~cm}$ from the sternum to the Aorta, RV and $C A B G$ graft crossing the midline within $1 \mathrm{~cm}$ of posterior to the sternumwere typically used for high risk upon sternal reentry [12-14].

A survey of 2046 significant bleeding during sternal entry showed that the most commonly injured structures were RV (39\%), Saphenous vein graft (SVG: 20\%), Aorta (15\%), IMA (12\%) and innominate vein (6\%) [15]. Radiologist and Surgeon must keep this in mind to find the relationship between the sternum and these structures when 3-D MDCTA is assessed preoperatively.

\subsection{Operative Strategy Based on 3-D MDCTA}

After assessing these structures, surgeons will consider the following for operative planning.

\subsubsection{Cannulation Strategy}

1) Direct central cannulation.

2) Guidewire placement for emergency.

3) Peripheral cannulation.

a) Femoral artery cannulation.

b) Axillary cannulation.

First step of operative decision making is cannulation strategy. Cannulation strategy must be decided prior to incision with a backup plan. If there is good distance from the sternum, sternotomy can be performed and direct central cannulation can be performed following mediastinal dissection. Mediastinal dissection should be performed around the Aorta and right atrium first so that cardiopulmonary bypass (CPB) can be established in case of emergency.

It is our common practice to place guidewire in femoral artery and femoral vein to prepare for emergency. Guidewire is inserted under transesophageal echocardiogram (TEE) guidance. If any structure is injured during sternal reentry, sternum is approximated and CPB is established following Seldinger technique placement of arterial and venous cannula.

If adhesions present, peripheral cannulation should be considered. Femoral artery/vein can be used. Axillary artery can be used when femoral artery use is concern (peripheral vascular disease, obesity etc). Our practice is to place $8-10 \mathrm{~mm}$ dacron graft to preserve distal flow.

\subsubsection{Cardiopulmonary Bypass}

1) Go on cardiopulmonary bypass prior to sternotomy.
2) Deep Hypothermic circulatory arrest.

3) No cardiopulmonary bypass.

In severe adhesions, consideration of establishing CPB prior to sternotomy should be made. This will allow decompression of RV and decreases the chances of injury during sternal reentry. Luciani, et al. reported their experience with 158 patients who underwent cardiopulmonary bypass prior to creating sternotomy [16]. This decision was made on the CT evidence of dense retrosternal adhesions, depressed ejection fraction or previous mediastinitis. Use of CPB prior to sternotomy was associated with less re-entry injuries, reduced operative time, less postoperative bleeding and shorter ICU stay.

Deep hypothermic circulatory arrest can be used for extreme cases with severe adhesion or injury to the aorta occurred. For low risk cases, no CPB will allow blood less dissection since no heparin is used prior to dissection.

\subsubsection{Sternotomy vs Non-Sternotomy}

1) Reoperative sternotomy-grafts in relation to the sternal wires.

2) Anterior thoracotomy.

3) Transcatheter treatment.

Access strategy can be altered depending on the operation being performed. If prior $\mathrm{CABG}$ patient with significant graft adhesion is undergoing mitral valve surgery, literature supports use of right thoracotomy for access [17]. Left thoracotomy can be used for reoperative CABG to circumflex artery and avoiding sternal entry [18].

If the patient has high risk comorbidity and high risk findings on 3-D MDCTA, consideration of transcatheter treatment (percutaneous coronary intervention for coronary disease, transcatheter valve replacements for valve disease) if indicated.

\subsubsection{Cancellation}

When the findings show extremely high risk, surgeon can decide to cancel the case. 3-D-CTMDA will aid this decision making. Report from Cleveland Clinic described 4\% cancellation in their 167 adult reoperative cardiac surgery series [14]. Patent RIMA with additional jump graft supplying a left dominant system crossing the sternal midline at an unsafe distance in a severe valvular disease patient was one of the examples used in this series. Other series report $6 \%-12 \%$ cancellation rate in their series $[13,19]$.

\subsection{Patient Images}

Figures 1(a) and (b) show the 3-D MDCTA on 65 years old male who underwent CABG (SVG to posterior descending artery) and came back for aortic valve replacement (AVR). Preoperative MDCTA showed SVG graft 


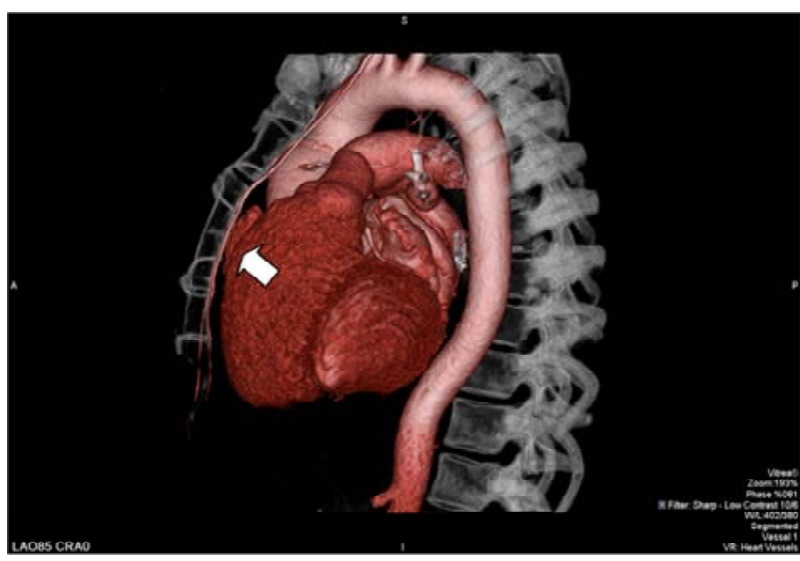

(a)

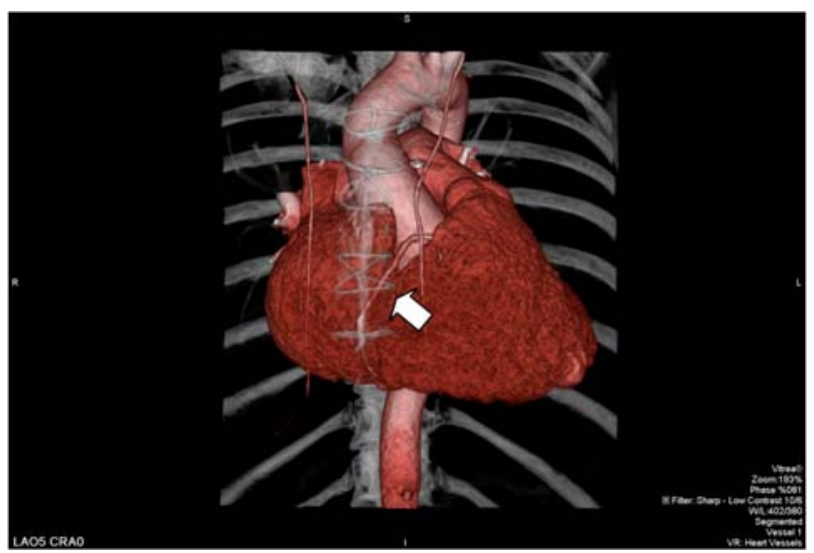

(b)

Figure 1. 65 years old male after CABG. Previous graft is seen below the sternum. Proximity of the graft and sternum was considered high risk. This patient underwent femoral artery cannulation prior to sternotomy. (Arrow shows the location of the SVG).

lying behind the sternum $<1 \mathrm{~cm}$ and was crossing midline. This was considered high risk and operative strategy was discussed preoperatively. Femoral artery cannulation was performed prior to sternal reentry. Careful dissection with anticipation of SVG behind the sternum allowed safe dissection of the SVG. No injury was encountered and AVR was performed successfully.

Figure 2 shows the 3-D MDCTA on 70-year-old male who presented for Aortic stenosis and underwent CABG (SVG to right coronary artery). He was scheduled for AVR and preoperative 3-D MDCTA was performed to assess the mediastinum. MDCTA showed previous SVG traversing the midline and was densely attached to the sternum. Preoperative strategy was changed to axillary artery cannulation and femoral vein cannulation. We had prepared to go on CPB prior to sternal reentry. During sternal reentry, SVG injury was encountered and CPB was established immediately. There were no hemodynamic instability or ST changes. Mediastinal dissection

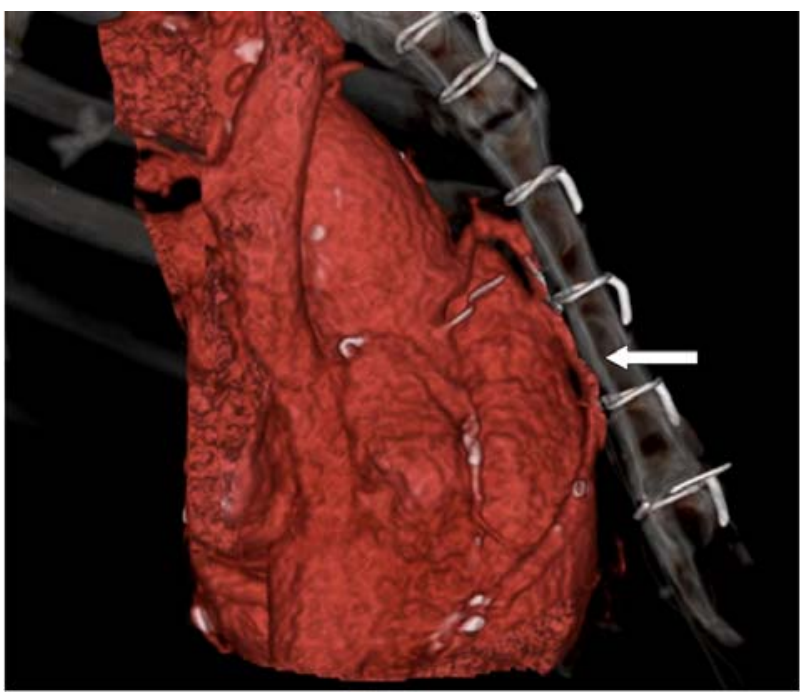

Figure 2. 70 years old, $M$ status post $\mathrm{CABG}$ with prior SVG graft to RCA. Graft was traversing the midline and was attached to the sternum (white arrow). Knowing this, we performed axillary artery cannulation and femoral vein cannulation. There was a SVG graft injury during entry and cardiopulmonary bypass was established immediately. Mediastinal dissection followed by SVG graft repair was performed primarily. No hemodynamic instability was encountered as well as ST changes.

was performed and SVG injury was repaired primarily. Rest of the procedure was conducted without any problem.

\section{DISCUSSION}

\subsection{Comparison to Chest X-Ray (CXR) and Angiography}

Gasparovic, et al. compared 3-D MDCTA and CXR/ coronary angiography in their series of 33 patients who underwent reoperative cardiac surgery after previous CABG [13]. The correlation for distance of the LIMA graft from midline and posterior sternum obtained by CTA and CXR was poor (correlation coefficient: $\mathrm{R}=$ 0.56 and 0.49 . The R for CTA and angiography was 0.54 for LIMA graft. One third of the CXR could not identify LIMA graft (from the clips) and $85 \%$ of patients could not obtain pertinent CTA finding from standard CXR and Angiography.

No injury to the LIMA was reported in this case series. This is significant improvement from 5.3\% injury rate from Cleveland clinic with perioperative infarction rate of $50 \%$ which CXR and angiography was used for preoperative imaging [20].

\subsection{Outcomes Using 3-D MDCTA}

Early report from Cremer, et al. assessed their 99 adult patient experiences that had reoperative coronary artery 
surgery with preoperative spiral CT without contrast angiography [21]. No MDCTA was used as well as 3-D reconstructions, but safe sternal reentry was obtained in $98 \%$ and only $2 \%$ had injury to vital structures. This opened the door for preoperative assessment using CT.

In their 33 patient series, Gasparovic, et al. reported $21 \%$ alteration in surgical strategy [13]. Two injuries to vital structures were encountered, right ventricle in 1 case, vein graft in 1 case, but no IMA and aortic injury. Operative mortality was $17 \%$.

Kamder, et al. reported the largest series to date in their 167 adult patients with reoperative cardiac surgery who had prior CABG [14]. They used contrast enhanced MDCTA for preoperative evaluation. The high risk findings were $<1 \mathrm{~cm}$ distance between chest wall and right ventricle or aorta $(24 \%)$ and graft crossing midline $<1$ $\mathrm{cm}$ anteroposteriorly (38\%). $49 \%$ had 1 or more high risk findings. $86 \%$ had alteration in surgical strategy: $8 \%$ nonmidline incision, 5\% deep circulatory hypothermic arrest, $11 \%$ initiation of peripheral CPB, 53\% extrathoracic vascular exposure before incision and $4 \%$ cancellation. Frequency of severe bleeding, injury to vital structures and 1-month mortality were $4.4 \%, 5 \%$ and $2.5 \%$. There was no difference in frequency of vital structure injury and severe bleeding between high-risk and lowrisk MDCTA groups, likely from adoption of preventive surgical strategies.

Maluenda, et al. reported 137 patients who underwent MDCTA prior to reoperative cardiac surgery and was compared to 227 patients who did not have MDCTA prior to reoperative cardiac surgery [12]. MDCTA group had lower incidence of perioperative myocardial infarction, shorter perfusion time and cross clamp time, total time in intensive care unit and lower volume of postoperative transfusion.

\subsection{Additional Information}

Additional information can be found during CTA assessment. In Gasparovic's report, 42\% had atherosclerotic ascending aortic and aortic arch disease and 3\% had ascending aortic aneurysm. Persistent left superior vena cava, innominate and superior vena cava stenosis was found in $9.1 \%$. Of these findings, atherosclerosis of the aorta carries significance. In case of unclampable aorta, cannulation stratery (peripheral cannulation) will be altered and may require deep hypothermic circulatory arrest to replace and clamp the aorta.

\subsection{Cost}

Goldstein, et al. reported their data on cost data in patients who underwent MDCTA prior to reoperative cardiac surgery and compared to group who did not undergo MDCTA [22]. \$1150 was charged to MDCTA patients for preoperative testing. MDCTA group had lower me- dian recovery room and nursing charges, but higher operative room charges. Despite the additional charge for MDCTA, MDCTA group had lower mean total hospital charges ( $\$ 163,000$ vs $\$ 192,000 ; p \leq 0.06)$.

\subsection{Upcoming Technology}

Dynamic MDCTA has recently been reported <ref Malguria, et al. "Static and Cine CT Imaging to Identify and Characterize Mediastinal Adhesions as a Potential Complication Undergoing Redo Sternotomy." AJR ACCEPTED FOR PUBLICATION NOT YET IN PRESS. In addition to the distance used in most MDCTA studies, this technique will take structure's movement into account, therefore called 4-D-MDCTA. For instance, if the $\mathrm{RV}$ is in close proximity to sternum yet has free movement, this means that it may not be adherent or that the adhesions are not severe. If the RV does not move at the attachment to the sternum, this likely indicates severe adhesion.

\section{CONCLUSION}

Although no randomized prospective study has been performed to prove the role of preoperative MDCTA, it is obvious that new piece of information provided by MDCTA will give important clues to the surgeons performing reoperative sternotomy. High risk findings will alter surgeon's operative strategy and may even lead to cancellation or seek other procedures such as transcatheter procedure. In conclusion, 3-D MDCTA provides important information in a high risk reoperative cardiac surgery and lowers the frequency of injury to vital structures.

\section{REFERENCES}

[1] Weintraub, W.S., Jones, E.L., Craver, J.M., Grosswald, R. and Guyton, R.A. (1995) In-hospital and long-term outcome after reoperativecoronary artery bypass graft surgery. Circulation, 9, II50-II57. doi:10.1161/01.CIR.92.9.50

[2] Shapira, I., Isakov, A., Heller, I., Topilsky, M. and Pines, A. (1999) Long-termfollow-up after coronary artery bypass grafting reoperation. Chest, 115, 1593-1597. doi:10.1378/chest.115.6.1593

[3] Yau, T.M., Borger, M.A., Weisel, R.D. and Ivanov, J. (2000) The changingpattern of reoperative coronary surgery: Trends in 1230consecutive reoperations. The Journal of Thoracic and Cardiovascular Surgery, 120, 156163. doi: $10.1067 / \mathrm{mtc} .2000 .106983$

[4] Stephan, W.J., O'Keefe, Jr. J.H., Piehler, J.M., et al. (1996) Coronaryangioplasty versus repeat coronary artery bypass graftingfor patients with previous bypass surgery. Journal of the American College of Cardiology, 28, 1140-1146. doi:10.1016/S0735-1097(96)00286-0

[5] Akl, E.S., Ozdogan, E., Ohri, S.K., et al. (1992) Early 
and long termresults of re-operation for coronary artery disease. British Heart Journal, 68, 176-180. doi:10.1136/hrt.68.8.176

[6] Fitzgibbon, G.M., Kafka, H.P., Leach, A.J., Keon, W.J., Hooper, G.D. and Burton, J.R. (1996) Coronary bypass graft fate and patient outcome: Angiographic follow-up of 5065 grafts related to survival andreoperation in 1388 patients during 25 years. Journal of the American College of Cardiology, 28, 616-626. doi:10.1016/0735-1097(96)00206-9

[7] Shimada, Y., Dixit, A., Fermanis, G. and Horton, D. (1998) Reoperation forrecurrent coronary artery disease: Results of 200 consecutivecases. Australian and New Zealand Journal of Surgery, 68, 729-734. doi:10.1111/j.1445-2197.1998.tb04661.x

[8] Fullerton, D.A., St Cyr, J.A., Fall, S.M. and Whitman, G.J. (1994) Protection of the patent internalmammary artery bypass graft from subsequent sternotomy. The Journal of Cardiovascular Surgery (Torino), 35, 499-501.

[9] Kaneko, T., Nauta, F., Borstlap, W., McGurk, S., Couper, G. and Cohn, L. (2012) The "no-dissection" technique is safe for reoperative aortic valvereplacement with a patent left internal thoracic artery graft. The Journal of Thoracic and Cardiovascular Surgery, 144, 1036-1041. doi:10.1016/j.jtcvs.2012.07.057

[10] Song, M.H., Ito, T., Watanabe, T., Nakamura, H. (2005) Multidetectorcomputed tomography versus coronary angiogram in evaluationof coronary artery bypass grafts. The Annals of Thoracic Surgery, 79, 585-588. doi:10.1016/j.athoracsur.2004.08.014

[11] Anders, K., Baum, U., Schmid, M., et al. (2006) Coronary artery bypassgraft (CABG) patency: Assessment with high-resolution submillimeter16-slice multidetectorrow computed tomography (MDCT) versus coronary angiography. European Journal of Radiology, 57, 336-344. doi:10.1016/j.ejrad.2005.12.018

[12] Maluenda, G., Goldstein, M.A., Lemesle, G., Weissman, G., Weigold, G., Landsman, M.J., Hill, P.C., Pita, F., Corso, P.J., Boyce, S.W., Pichard, A.D., Waksman, R. and Taylor, A.J. (2010) Perioperative outcomes in reoperative cardiac surgery guided by cardiac multidetector computed tomographic angiography. American Heart Journal, 159, 301-306. doi:10.1016/j.ahj.2009.11.005

[13] Gasparovic, H., Rybicki, F.J., Millstine, J., Unic, D., Byrne, J.G., Yucel, K. and Mihaljevic, T. (2005) Three dimensional computedtomographic imaging in planning the surgical approach for redo cardiac surgery after coronary revascularization. European Journal Cardio-Thoracic Surgery, 28, 244-249. doi:10.1016/j.ejcts.2005.03.024

[14] Kamdar, A.R., Meadows, T.A., Roselli, E.E., Gorodeski, E.Z., Curtin, R.J., Sabik, J.F., Schoenhagen, P., White, R.D., Lytle, B.W., Flamm, S.D. and Desai, M.Y. (2008) Multidetector computed tomographic angiography in plan- ning of reoperative cardiothoracic surgery. The Annals of Thoracic Surgery, 85, 1239-1245.

doi:10.1016/j.athoracsur.2007.11.075

[15] Follis, F.M., Pett, Jr. S.B., Miller, K.B., Wong, R.S., Temes, R.T. and Wernly, J.A. (1999) Catastrophic hemorrhage on sternal reentry: Still a dreaded complication? The Annals of Thoracic Surgery, 68, 2215-2219. doi:10.1016/S0003-4975(99)01173-X

[16] Luciani, N., Anselmi, A., De Geest, R., Martinelli, L., Perisano, M. and Possati, G. (2008) Extracorporeal circulation by peripheral cannulation before redo sternotomy: Indications and results. The Journal of Thoracic and Cardiovascular Surgery, 136, 572-577. doi:10.1016/j.jtcvs.2008.02.071

[17] Byrne, J.G., Aranki, S.F., Adams, D.H., Rizzo, R.J., Couper, G.S. and Cohn, L.H. (1999) Mitral valve surgery after previous CABG with functioning IMA grafts. The Annals of Thoracic Surgery, 68, 2243-2247. doi:10.1016/S0003-4975(99)01120-0

[18] Byrne, J.G., Aklog, L., Adams, D.H., Cohn, L.H. and Aranki, S.F. (2001) Reoperative CABG using left thoracotomy: A tailored strategy. The Annals of Thoracic Surgery, 71, 196-200. doi:10.1016/S0003-4975(00)02182-2

[19] Aviram, G., Sharony, R., Kramer, A., Nesher, N., Loberman, D., Ben-Gal, Y., Graif, M., Uretzky, G. and Mohr, R. (2005) Modification of surgical planning based on cardiac multidetector computed tomography in reoperative heart surgery. The Annals of Thoracic Surgery, 79, 589595. doi:10.1016/j.athoracsur.2004.07.012

[20] Gillinov, A.M., Casselman, F.P., Lytle, B.W., et al. (1999) Injury to a patent left internal thoracic artery graft at coronary reoperation. The Annals of Thoracic Surgery, 67, 382-386. doi:10.1016/S0003-4975(99)00009-0

[21] Cremer, J., Teebken, O.E., Simon, A., Hutzelmann, A., Heller, M. and Haverich, A. (1998) Thoracic computed tomography prior to redo coronary surgery. European Journal Cardio-Thoracic Surgery, 13, 650-654. doi:10.1016/S1010-7940(98)00087-6

[22] Goldstein, M.A., Roy, S.K., Hebsur, S., Maluenda, G., Weissman, G., Weigold, G., Landsman, M.J., Hill, P.C., Pita, F., Corso, P.J., Boyce, S.W., Pichard, A.D., Waksman, R. and Taylor, A.J. (2013) Relationship between routine multi-de- tector cardiac computed tomographic angiogra- phy prior to reoperative cardiac surgery, length of stay, and hospital charges. The International Journal of Cardiovascular Imaging, 29, 709-717. doi:10.1007/s10554-012-0133-2 